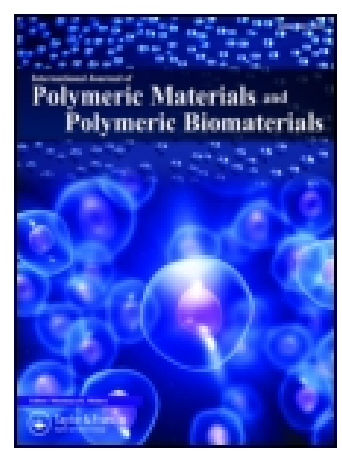

International Journal of Polymeric Materials and Polymeric Biomaterials

ISSN: 0091-4037 (Print) 1563-535X (Online) Journal homepage: http://www.tandfonline.com/loi/gpom20

\title{
Magnetic field responsive methylcellulose- polycaprolactone nanocomposite gels for targeted and controlled release of 5-fluorouracil
}

\section{Dariush Nikjoo \& Ayse Z. Aroguz}

To cite this article: Dariush Nikjoo \& Ayse Z. Aroguz (2016) Magnetic field responsive methylcellulose-polycaprolactone nanocomposite gels for targeted and controlled release of 5-fluorouracil, International Journal of Polymeric Materials and Polymeric Biomaterials, 65:8, 421-432, DOI: $10.1080 / 00914037.2015 .1129954$

To link to this article: http://dx.doi.org/10.1080/00914037.2015.1129954

Accepted author version posted online: 22

Dec 2015.

Submit your article to this journal $₫$

Џll Article views: 44

View related articles

View Crossmark data ־ 


\title{
Magnetic field responsive methylcellulose-polycaprolactone nanocomposite gels for targeted and controlled release of 5 -fluorouracil
}

\author{
Dariush Nikjoo and Ayse Z. Aroguz \\ Department of Chemistry, Faculty of Engineering, Istanbul University, Avcilar, Istanbul, Turkey
}

\begin{abstract}
5-Fluorouracil loaded magnetic field sensitive methylcellulose and polycaprolactone gels were prepared and characterized by FTIR, XRD, TGA, SEM, and VSM. Swelling analysis supplied important information on drug diffusion properties. The release profile of gels was investigated in different buffer solutions and the highest release values were observed at $\mathrm{pH}=7.2$. Release kinetic was analyzed using an empirical equation to clarify the transport properties of drug. The effects of nanoparticle concentration and applying external magnetic field were investigated on release profile. The results indicated that the drug release decreased by both, applying external magnetic field and increasing the concentration of $\mathrm{Fe}_{3} \mathrm{O}_{4}$ nanoparticles.
\end{abstract}

\section{GRAPHICAL ABSTRACT}

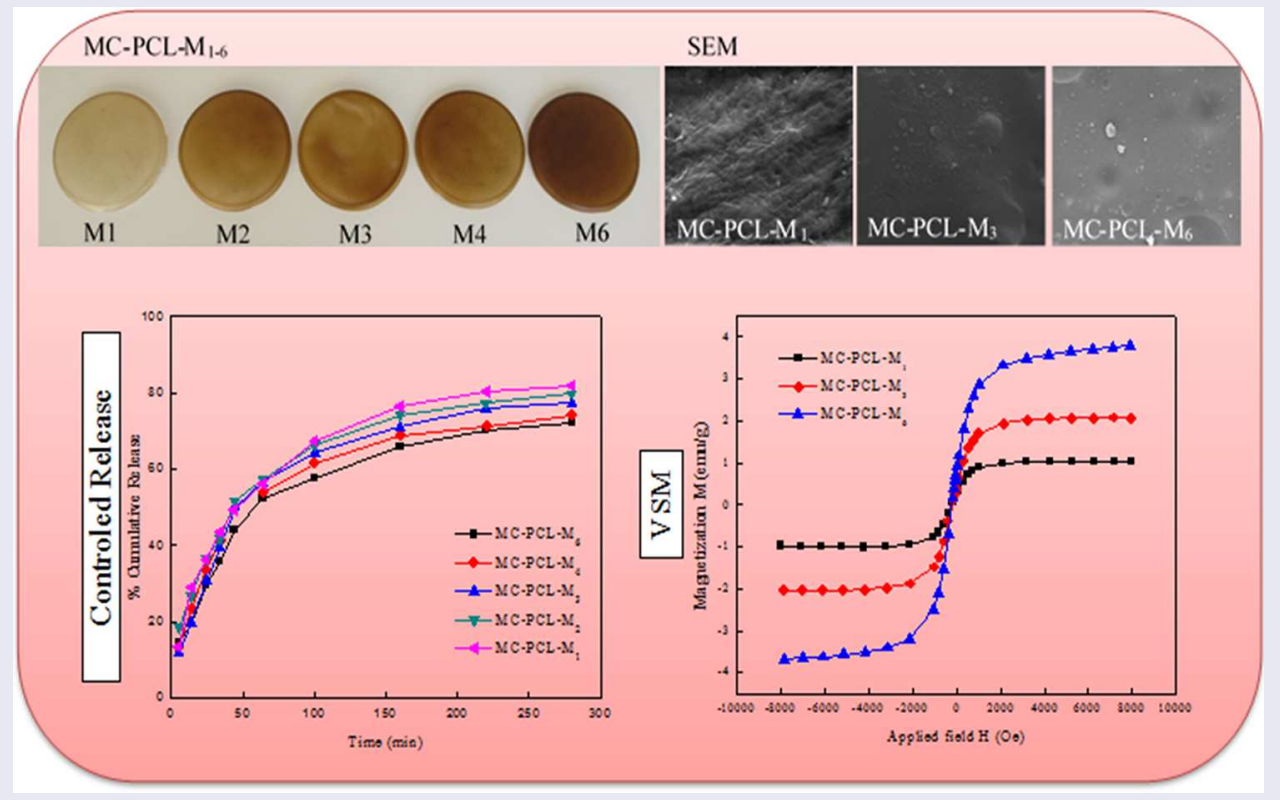

\section{ARTICLE HISTORY}

Received 29 June 2015

Accepted 7 December 2015

\section{KEYWORDS}

5-fluorouracil; magnetic; methylcellulose;

nanoparticle;

polycaprolactone; release

\section{Introduction}

Polysaccharides are ubiquitous biopolymers built up from monosaccharide and they are a class of natural carbohydrates polymers that have been extensively used in the food and pharmaceutical industry and also for drug delivery systems. Methylcellulose (MC), a carbohydrate polymer and ether derivative of cellulose, is soluble in water. MC is broadly used as a binder or thickener in pharmaceuticals, foods, ceramics, and emulsifier in food, hair shampoos, toothpastes, liquid soaps, and cosmetic applications. MC demonstrates a specific lower critical solution temperature (LCST) phase behavior and suffers a two-stage thermo reversible gelation in aqueous solution with increasing temperature when the concentration is above a critical solution temperature value [1,2]. Researchers worked on the effect of salts on the gelation temperature of MC [3-5]. Furthermore, some additives, such as glycolic, alcoholic, and polyester resins can cause mutation on gelation properties of MC [6,7].

Pure MC solution is in the form of gel at room temperature and second gelation temperature is always in the region of 50 $70^{\circ} \mathrm{C}$. Therefore, pure MC cannot be applied as a product for gelation in vivo at $37^{\circ} \mathrm{C}$. One of the methods for modifying and improving of the physical properties is the blending method,

CONTACT Ayse Z. Aroguz aroguz@istanbul.edu.tr Department of Chemistry, Faculty of Engineering, Istanbul University, 34320 Avcilar, Istanbul, Turkey. Color versions of one or more of the figures in the article can be found online at www.tandfonline.com/gpom. 
which increases the range of application of polymeric materials. However, investigation of interactions and miscibility of the polymer mixtures is an important criterion in the preparation of different polymeric blends. There are several techniques for studying the interactions and miscibility of the polymers [8,9]. Liang et al. used MC and alginate hydrogel blended with $\mathrm{NaCl}$ and have used it as carrier for site-specific protein delivery in the intestine [10]. Sodium alginate-methylcellulose microspheres have been prepared by Babu et al. [11] and they used these microspheres for the controlled release of nifedipine. Liu et al. [12] studied poly( $\mathrm{N}$-isopropylacrylamide)-g-MC as a fast reversible thermosensitive copolymer. A blend of hyaluronan and MC has been synthesized for investigation the delivery of therapeutic agents in spinal cord injury [13]. Chitosan and methylcellulose blend hydrogels have commonly been used as engineering scaffolds [1].

One of the earliest polymers synthesized in the early 1930s is polycaprolactone (PCL) [14]. Following efforts to find new synthetic polymers that were degradable by microorganisms, PCL became commercially available and recently, it has propelled into biomaterials area more rapidly [15]. PCL is a semicrystalline, aliphatic polyester with low glass transition temperature and melting point and it has good biocompatibility and degradability [16-19]. PCL is not biodegradable in the body of animals and human because of the lack of suitable enzymes [20]. Furthermore, PCL can be mixed with other biodegradable polymers to provide new biodegradable blend materials with improved and better properties than those of relative components [21]. PCL can also be blended with cellulose derivatives and other polymers for manipulating the rate of drug release from the scaffold. There are some reports in blends of PCL and cellulose nitrate [22], cellulose butyric ester $[23,24]$, cellulose acetate-butyrate [16,25], cellulose acetate $[16,26,27]$, long-chain ester of cellulose [9], ethylcyanoethyl cellulose [28], methylcellulose [29], poly(3- hydroxybutyrate) [30,31], and other polymers such as chitin or its derivative [32].

5-Fluoro-1,2,3,4-tetrahydropyrimidine-2,4-dione, or 5fluorouracil (5-FU), is used as one of the popular and effective anticancer drugs and its molecular weight is $130 \mathrm{~g} / \mathrm{mol}$. It is partially soluble in water with a maximum solubility of $1 \mathrm{mg} / \mathrm{mL}$. 5-FU is a therapeutic agent, widely has been used to treat breast, nonmelanoma skin, colorectal, and pancreatic cancer [33,34]. 5-FU is administered orally, topically as cream (Effudex) or intravenously (Adrucil) and its chemotherapic effect is based on inhibition of DNA synthesis and RNA functions in cancer tissue. Actually, 5-FU acts as antimetabolite in synthesis of thymidine that is essential substrate for DNA synthesis [35].

However the conventional administration of drug display high toxicity and many side effects [36]. Site-selective drug delivery is a vehicle to overcome the side effect of drug through reduction of the drug amount in the residue of the body that can cause unwanted side effects. Controlled drug delivery exerts a desired strategy for the optimization of chemotherapy and helps drug to be more effective and safe in the body. The controlled release of 5-FU from chitosan-alginate microcapsules has been investigated [37]. 5-FU bioadhesive patches have been used for local delivery to the uterine cervix and these patches were based on ethylcellulose and polyvinylpyrrolidone [38,39]. 5-FU loaded chitosan and Eudragit nanoparticles have been used for controlled release monitoring [40]. Chitosan and acrylamide (AAm) and/or N-hydroxymethyl acrylamide (HMA) based semiinterpenetrating network hydrogels were synthesized and potential of drug release have been studied for 5-FU release as model drug [41]. Some other reports for controlled and targeted delivery of 5-FU are performed by poly (hydroxy ethyl methacrylate-co-acrylamidoglycolic acid) based hydrogels [42], interpolymeric chitosan hydrogels [43], and chitosan based multilayer copolymeric system [44].

The aim of this research was to investigate the release profile of 5-FU, as model drug, from MC-PCL magnetic field responsive gels prepared and characterized in this work. The effect of $\mathrm{pH}$ and external magnetic field on drug release profile was studied. The data obtained from the experiments have been fitted using an empirical equation to clarify the properties of transport of drug release through the polymeric matrices. There is no work reported on the release profile of 5-FU from MC-PCL blend and magnetic nanoparticles up to now.

\section{Experimental}

\subsection{Materials}

Methylcellulose $\quad(\mathrm{Mn}=40000)$, polycaprolactone $\quad(\mathrm{Mn}$ $=80,000), \mathrm{Fe}_{3} \mathrm{O}_{4}$ nanoparticles $(50-100 \mathrm{~nm})$ and glutaraldehyde $(50 \%$ aqueous solution; GA) were purchased from Sigma-Aldrich Chemical Co. 5-FU is purchased from Alfa Aesar company. Buffer solutions were prepared by using potassium hydrogen phthalate $\left(\mathrm{KHC}_{8} \mathrm{H}_{4} \mathrm{O}_{4}\right)$, potassium dihydrogen phosphate $\left(\mathrm{KH}_{2} \mathrm{PO}_{4}\right)$, hydrochloric acid $(\mathrm{HCl})$, sodium bicarbonate $\left(\mathrm{NaHCO}_{3}\right)$, and sodium hydroxide $(\mathrm{NaOH})$ [45]. All buffer chemicals were Merck (Hohenbrunn, Germany) products. Distilled water was used for the preparation of hydrogels and buffer solutions.

\subsection{Preparation of $M C-P C L$ films}

To study the influence of different blend compositions on the properties of MC-PCL films, a series of MC-PCL films were prepared by adjusting the feed amounts of MC/PCL as 100/ $0,95 / 5,90 / 10,85 / 15,75 / 25,0 / 100 \mathrm{w} / \mathrm{w}$. An appropriate amount of MC solution was prepared in glacial acetic acid by stirring continuously at room temperature and proper amount of PCL related to the composition given above were added into this solution to prepare particular blend solution and the mixture was stirred at room temperature for $60 \mathrm{~min}$. Then the obtained mixtures poured in Teflon Petries and were dried at room temperature and finally dried under vacuum oven until constant weight at $37^{\circ} \mathrm{C}$ (Figure 1a). The average thickness of the dry films was found to be (0.111 \pm $0.001 \mathrm{~mm}$ ). MC/PCL crosslinked gel films (MC-PCL-F$\mathrm{GA}_{0.5-4.0}$ ) were prepared using MC/PCL (95/5) sample by adding GA solution, as crosslinker, in different concentrations. The effect of the amount of the crosslinker was studied using various GA concentrations as $(0.5 \%, 1 \%, 2 \%, 3 \%$, and $4 \%)$. The substrate of GA in the formula of (MC-PCL-F-GA ${ }_{0.5-4.0}$ ) 


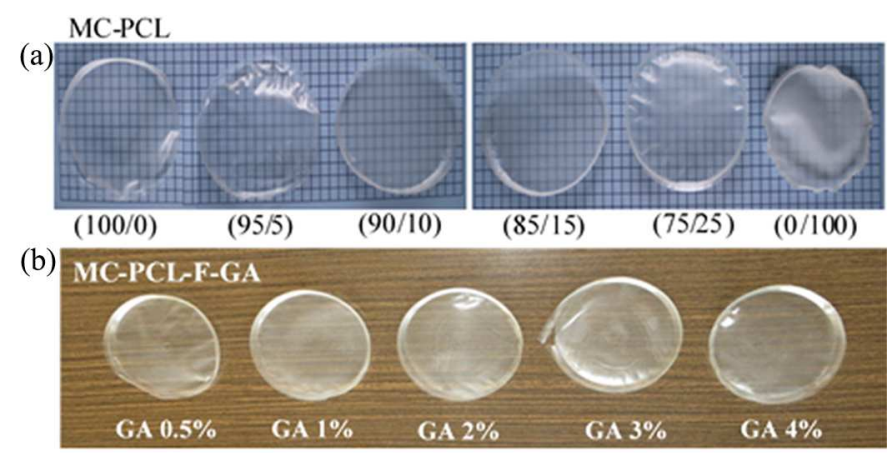

(c) MC-PCL-M

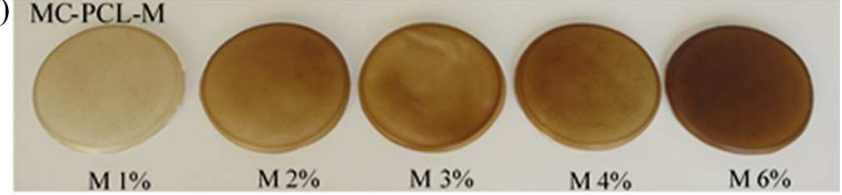

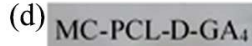

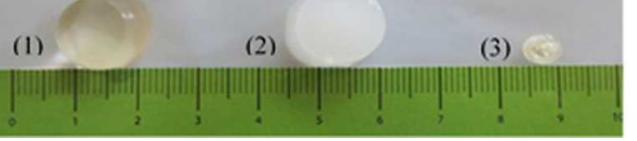

Figure 1. Optical appearances of (a) MC-PCL blend films, (b) MC-PCL-F-GA $0.5-4$ gel films, (c) MC-PCL-M ${ }_{1-6}$ magnetic gel films, and (d) MC-PCL-D-GA $A_{4}$ gel disc (1: after cutting, 2: after one week maintain in distilled water and 3: dry disc).

shows the weight percentages of the GA in the gel films changing from 0.5 to 4.0 , (Figure $1 \mathrm{~b}$ ). The average thickness of the dry films (MC-PCL-F-GA (M-5-4.0 ) was found to be $(0.116 \pm 0.001 \mathrm{~mm})$.

For preparation of drug loaded MC/PCL gel films (MCPCL-F-GA $\mathrm{G}_{2}$ ), 5-FU was added to the blend solution and dissolved completely with weight fraction of $0.5 \%$ of mixture solution. Then GA solution ( $2 \%)$ was added as crosslinker. Subsequently, the mixture was gradually poured in a Teflon Petri dish and dried at room temperature. Finally, the samples were dried under vacuum oven until constant weight at $37^{\circ} \mathrm{C}$.

\subsection{Preparation of crosslinked $M C / P C L$ disks}

For preparation of MC/PCL (95/5) gel discs (MC-PCL-D$\left.\mathrm{GA}_{3-6}\right), \mathrm{MC}$ and PCL solutions $(2 \% \mathrm{w})$ were first prepared in the glacial acetic acid separately. The stock solutions were prepared by mixing MC and PCL solutions with the ratio $(95 / 5, \mathrm{w} / \mathrm{w})$ in a beaker. GA solutions (concentration $3 \%$, $4 \%, 5 \%$, and $6 \%$ ) were added to study of the influence of crosslinker concentration. The mixture was poured into a syringe and then sealed and immersed for $24 \mathrm{~h}$ in a water bath at $25^{\circ} \mathrm{C}\left( \pm 0.01^{\circ} \mathrm{C}\right)$. At the end of the crosslinking reaction period, the syringe was cut carefully from the head side and hydrogel was removed from of syringe with assistance of plunger without destroying the hydrogel. The obtained cylindrical hydrogel was then sliced into small discs $(0.8-1.0 \mathrm{~cm}$ in length) and were stored in distilled water for one week. The water was changed daily, in order to remove the unreacted linear polymers and GA. The hydrogel samples were dried, first in the air at room temperature and then in the vacuum oven at $37^{\circ} \mathrm{C}$ (Figure 1d). The average thickness and diameter of the dry discs (MC-PCL-D-GA $A_{3-6}$ ) was found to be
$2.543 \pm 0.001 \mathrm{~mm}$ and $6.768 \pm 0.001 \mathrm{~mm}$, respectively. For preparation of drug loaded MC/PCL gel discs (MC-PCL-D$\mathrm{GA}_{4}$ ), 5-FU was added to the blend solution and dissolved completely with weight fraction of $0.5 \%$ of mixture solution. Then GA solution with concentration of $4 \%$ was added as crosslinker. The rest of the procedure is the same as explained for preparation of the discs.

\subsection{Preparation of magnetic MC-PCL films}

Magnetic MC/PCL (95/5) gel films (MC-PCL-M ${ }_{1-6}$ ) were prepared at the same conditions as mentioned for the MC/PCL (95/5) films. In this case, $\mathrm{Fe}_{3} \mathrm{O}_{4}$ nanoparticles with various weight percentage $(1 \%, 2 \%, 3 \%, 4 \%, 6 \%)$ were added to the mixing solutions of MC and PCL after stirring at room temperature for $60 \mathrm{~min}$ and the effect of nanoparticles altering in the films was studied. The sonication bath (Protech) was used to obtain a homogenous nanoparticle and blend solution.

For the preparation of drug loaded magnetic MC/PCL (95/5) gel films, 5-FU was added to the blend solution and dissolved completely with weight fraction of $0.5 \%$ of mixture solution. Then different compositions of $\mathrm{Fe}_{3} \mathrm{O}_{4}$ nanoparticles $(1 \%, 2 \%, 3 \%, 4 \%, 6 \%)$ were added to mixture. The sonication bath was used to obtain a homogenous mixture of the nanoparticle and blend solution. Finally, GA solution (2\%) was added as crosslinker and subsequently, the mixture was gradually poured in a Teflon Petri dish and was dried at room temperature then dried under vacuum oven at $37^{\circ} \mathrm{C}$ until constant weight (Figure 1c). The average thickness of the dry drug loaded magnetic films (MC-PCL- $\mathrm{M}_{1-6}$ ) was found to be $0.128 \pm 0.001 \mathrm{~mm}$.

\subsection{Magnetic field generator}

A magnetic field was generated at the center of a conductor coil where a direct electric current (DC) passed through it. The coil was made of copper tape $(0.45 \mathrm{~mm}$ radius). A total of 400 turns of the conductor tape were wrapped in a spiral, yielding an outside diameter of $6.25 \mathrm{~cm}$ and center opening diameter of $5.25 \mathrm{~cm}$. The coil's inductance and resistance were determined to be $4.198 \Omega$. DC current was passed through the coil by a power supply (Gw Instek GPS-3030DD). A magnetic field of $24.2 \mathrm{mT}$ was measured at the coil's center at $5 \mathrm{~A}$ using an axial probe Phywe Teslameter.

The 5A current passing through the coil's DC resistance of $4,198 \Omega$ caused an increase in the temperature. Furthermore, much of the heat was concentrated at the coil's center, where the sample was placed, causing a warming of the samples. Double-walled reactors connected to the thermostatic bath and fan-cooling techniques were used to keep the temperature at the constant range at the center of coil. The picture of the magnetic field generator is given in Figure 2.

\subsection{Characterization of MC-PCL gels}

\subsubsection{Optical appearances of gels}

The optical appearances of MC-PCL films, discs and magnetic films were recorded by a digital camera (Canon, D90), and they are given in Figure 1. 


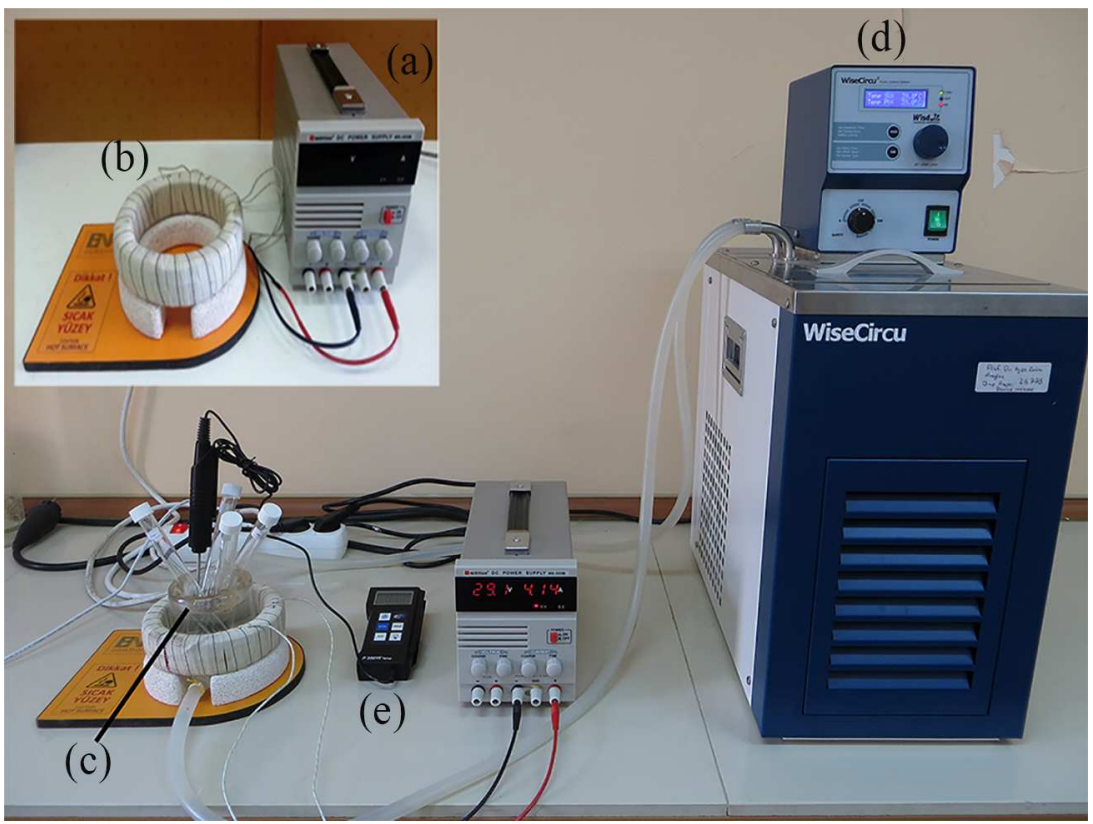

Figure 2. The magnetic field generator consists of a power supply (a) that passes a DC current to the copper coil (b). The sample temperature is kept constant by a fans and a double-walled reactor (c) connected to the thermostatic bath (d) as a water cooling-system. Digital thermometer (e).

\subsubsection{Film and disc thickness}

The thickness of the films along with the thickness and diameter of the discs were measured using a digital micrometer with an accuracy of $0.001 \mathrm{~mm}$. Thickness and diameter were measured at five different locations across the films and discs and used for calculating the average and relative standard deviation.

\subsubsection{FTIR analysis}

Both MC-PCL and magnetic MC-PCL gel films were characterized by ATR technique between 400 and $4000 \mathrm{~cm}^{-1}$ with using Spectrum One, Perkin-Elmer (USA) FTIR equipment.

\subsubsection{XRD analysis}

XRD patterns of the investigated gel films were obtained using DMAX-2200 X-ray diffractometer (Rigaku Company, Japan) with $\mathrm{Cu} \mathrm{Ka}$ tube at $40 \mathrm{kV}$ and $30 \mathrm{~mA}$.

\subsubsection{TGA analysis}

The gel films (10-20 mg) were subjected to thermogravimetric analysis (TGA) to determine their thermal stability and decomposition characteristics using Linseis STA PT 1750 TGA analyzer in the temperature range of $25-800^{\circ} \mathrm{C}$ at a heating rate of $20^{\circ} \mathrm{C} / \mathrm{min}$, with air flushed at $35-40 \mathrm{~mL} / \mathrm{min}$.

\subsubsection{SEM and SEM-EDS analysis}

Scanning electron microscopy (SEM) was used to investigate the surface morphology of the gels. The SEM images of the magnetic MC-PCL gel films were taken by FEI Quanta 450 FEG model SEM. The dry gels were coated with gold layer using sputter-coating, and their SEM and SEM-EDS pictures were taken. Element compositions $(\mathrm{C}, \mathrm{O}$, and $\mathrm{Fe}$ ) of the samples were investigated by the energy-dispersive X-ray spectroscopy (EDS) studies [46,47]. In the EDS spectrum, each element shows characteristic X-rays that are exhibited as peaks at specific energy levels. Furthermore, atomic resolution chemical mapping using EDS was used to depict the distribution of the elements in the matrices of samples.

\subsubsection{VSM analysis}

The Magnetic properties of samples were investigated using a computer controlled home-made vibrating sample magnetometer (VSM) at Istanbul Technical University with a sensitivity of $10^{-5} \mathrm{emu}$ and magnetic field up to $8 \mathrm{kOe}$ at room temperature.

\subsubsection{Swelling measurements}

The gravimetric method was used for the investigation of the effects of GA content in the samples and $\mathrm{pH}$ of medium on the equilibrium swelling values (ESVs) of the gel films and discs. ESVs of both gel films and disks were determined in buffer solutions with different $\mathrm{pH}$ values $(2.1,4.0,7.2,10.0)$ at constant ionic strength $(I=0.08 \mathrm{M})$ and $37^{\circ} \mathrm{C}$. The $\mathrm{pH}$ values of all buffer solutions were measured by a $\mathrm{pH}$ meter (Chebios $\mathrm{T} 620$ ) and it was detected that there is no differences between the theoretical and experimental $\mathrm{pH}$ values of buffer solutions. The ionic strength of the prepared buffer solutions was kept constant at $0.08 \mathrm{M}$ by the addition of $\mathrm{NaCl}$ [48]. A certain amount $\left(\mathrm{W}_{\mathrm{d}}\right)$ of dry gel film or disk was immersed in buffer solution at $37^{\circ} \mathrm{C}$ for $24 \mathrm{~h}$ in order to obtain the swelling equilibrium value. At the end of the swelling period, the swollen gel film or disk pieces were taken out of the buffer solution and the excess water was removed using a piece of filter paper, and the swollen film/disc was weighed $\left(\mathrm{W}_{\mathrm{s}}\right)$. The following equation was used to determine the ESV values of the gel films and disk by gravimetric method:

$$
E S V\left(g_{H_{2} \mathrm{O}} / g_{\text {polymer }}\right)=\left(W_{s}-W_{d}\right) / W_{d}
$$

\subsubsection{Drug release measurement}

For drug release measurements, drug loaded films and discs were suspended in glass tubs containing $20 \mathrm{~mL}$ of the buffer 
solutions and incubated at $37^{\circ} \mathrm{C}$. At the appropriate time intervals the amount of 5-Fluorouracil, released from the drug loaded films to the solutions was measured by UV spectrophotometer (PG Instruments T80 model UV/VIS spectrophotometer) at $266 \mathrm{~nm}$. Afterward, an equal volume of the same solution medium was added to the tubes to keep the volume constant. Two typical buffer solutions, $\mathrm{pH}=2.1$ (potassium chloride $-\mathrm{HCl}$ ) and $\mathrm{pH}=7.2$ (potassium dihydrogen phosphate- $\mathrm{NaOH}$ ) were used for the controlled release studies. The ionic strength of mentioned buffer solutions was carefully adjusted to a relatively same level by adding an appropriate amount of $\mathrm{NaCl}$. All the experiments were done in twice or triplicates. Data getting from the UV absorbance were then changed to the concentration values according to the calibration curve of the drug in corresponding buffer solutions. Then, the accumulative release percentage was calculated as a function of time.

The well-known Korsmeyer-Peppas equation was used to estimate the drug release kinetic mechanism of synthesized gels [49]. The classical Korsmeyer-Peppas equation is given as

$$
\frac{M_{t}}{M_{\infty}}=K t^{n}
$$

The linear form of the Eq. 2 is

$$
\ln \left(\frac{M_{t}}{M_{\infty}}\right)=\ln K+n \ln t
$$

The plots of $\ln \left(M_{t} / M_{\infty}\right)$ versus $\ln t$ give a straight line with the slope of $n .\left(M_{t} / M_{\infty}\right)$ is the fraction of drug released after time $t$ relative to the amount of measured cumulative drug release at infinite time, $\mathrm{n}$ is diffusion exponent and shows the mode of drug transport, and $\mathrm{k}$ is a constant. This equation can satisfactory be used to explain the release of drug from the polymeric matrix.

The value of $\mathrm{n}<0.5$ shows Fickian diffusion from the polymer matrix with respect to gel films. Furthermore, the value of $\mathrm{n}$, in the range of $0.5-1$ shows non-Fickian transport and $\mathrm{n}=1$ refers to Case II (relaxational) transport. Finally, and $n>1$ refer to super case II transport mechanism. For cylindrical shaped matrices, $0.45 \leq \mathrm{n}$ corresponds to a Fickian diffusion transport, $0.45<\mathrm{n}<0.89$ to non-Fickian transport, $\mathrm{n}=0.89$ to Case II (relaxational) transport, and $n>0.89$ to super case II transport. The obtained data from in vitro drug release studies were plotted as logarithmic values of the cumulative drug release versus the time of the logarithmic value as given in Eq. $3[50,51]$.

\subsubsection{Drug release measurement under magnetic field}

The release profile of magnetic MC-PCL films was studied at magnetic field strengths of $24.2 \mathrm{mT}$ at $5 \mathrm{~A}$, for $300-400 \mathrm{~min}$. Each experiment was done in triplicate. A ventilator was used over the copper coil and water was pumped through the double-walled container to maintain the temperature of the samples constant at $37^{\circ} \mathrm{C}$. The samples were exposed to the appropriate frequency in the magnetic field by placing each sample in a $20 \mathrm{~mL}$ glass tubes at the center of the copper coil where is the place of the strongest magnetic field. The sample solutions were withdrawn at appropriate time intervals and the amount of released 5-FU was measured by UV spectrophotometer. The same procedure was followed for all drug release measurements.

\section{Results and discussion}

\subsection{Characterization of MC-PCL gels}

FTIR spectra of MC and PCL recorded by ATR technique are given in Figure 3. In Figure 3, the peak at $3722 \mathrm{~cm}^{-1}$ is attributed to stretching vibrations of $\mathrm{O}-\mathrm{H}(v \mathrm{O}-\mathrm{H})$ bond. The stretching vibration band of $\mathrm{C}-\mathrm{H}$ is shown at $2679 \mathrm{~cm}^{-1}$. The peak at $1744 \mathrm{~cm}^{-1}$ is assigned to stretching vibration band of carbonyl group $(v \mathrm{C}=\mathrm{O})[52,53]$. At $1476 \mathrm{~cm}^{-1}$ the peak is related to plane bending of $\mathrm{C}-\mathrm{OH}$ and symmetric bending of $\mathrm{CH}_{3}$ is observed at $1333 \mathrm{~cm}^{-1}$. The peak at $1028 \mathrm{~cm}^{-1}$ is contributed to $\mathrm{C}-\mathrm{O}$ stretching from asymmetric oxygen bridge and the peak at $938 \mathrm{~cm}^{-1}$ is related to ring stretching [52-54].

Figure 3 shows the FTIR spectrum of pure PCL. The peak at $3749 \mathrm{~cm}^{-1}$ is assigned to stretching vibration of $\mathrm{O}-\mathrm{H}$ bond. The peaks at 2944 and $2863 \mathrm{~cm}^{-1}$ are attributed to asymmetric and symmetric $\mathrm{CH}_{2}$ stretching vibration, respectively. The peak at $1731 \mathrm{~cm}^{-1}$ is associated to carbonyl stretching vibration and at $1293 \mathrm{~cm}^{-1}$ is related to $\mathrm{C}-\mathrm{O}$ and $\mathrm{C}-\mathrm{C}$ stretching in crystalline phase. The asymmetric and symmetric $\mathrm{C}-\mathrm{O}-\mathrm{C}$ stretching vibration bands are observed at $1240 \mathrm{~cm}^{-1}$ and $1160 \mathrm{~cm}^{-1}$ [55-58]. The peak at $1160 \mathrm{~cm}^{-1}$ is ascribed to $\mathrm{C}-\mathrm{O}$ and $\mathrm{C}-\mathrm{C}$ stretching in the amorphous phase [55-57].

The FTIR spectrum of blends consists of MC-PCL recorded by ATR technique is given in Figure 3. The stretching vibration peak of carbonyl group of $\mathrm{MC}$ shifted to a higher wavenumber $(1723,1727,1731,1732)$ with increase in PCL content in MC-PCL from $5 \%$ to $25 \%$. This result indicates that the interaction between two polymers decrease the intensity of the band due to the stretching vibration frequency of the carbonyl bond and it shifts to the lower frequency. There are two possible reasons for this shift: first one is the interaction between $\mathrm{C}-\mathrm{H}$ and $\mathrm{O}=\mathrm{C}-$, and the second one is dipoledipole interactions between $\mathrm{C}=\mathrm{O} \cdots \mathrm{O}=\mathrm{C}$ or $\mathrm{C}=\mathrm{O} \cdots \mathrm{O}-\mathrm{C}$ [59]. This result was in good agreement with the reports on

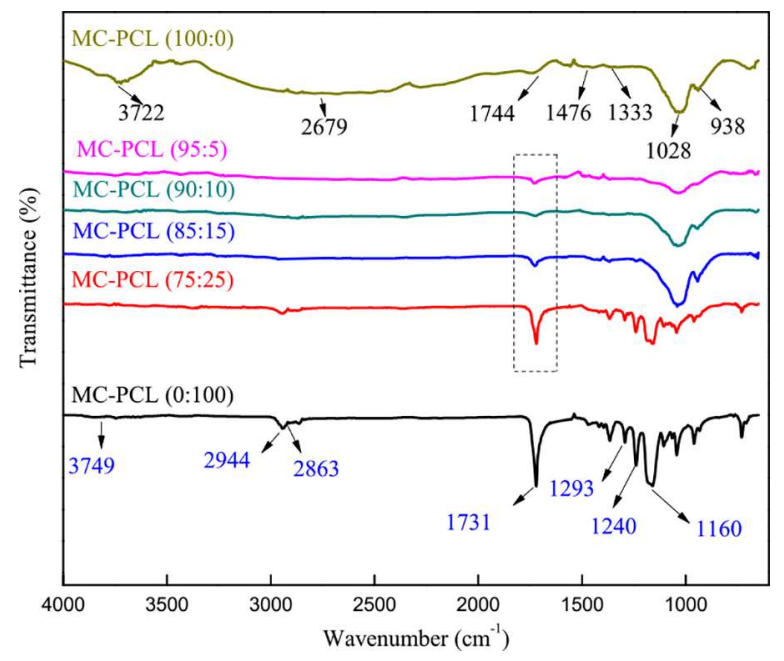

Figure 3. FTIR spectra of $M C, P C L$, and $M C-P C L$ blend films taken by ATR method. 
the other blends as poly(vinylphenol)/PCL, PCL/chlorinated polypropylene, and poly (e-caprolactone)/long-chain ester of cellulose $[9,59,60]$.

Figure 4a shows the FTIR spectrum of 5-FU, drug loaded and crosslinked MC-PCL-F-GA ${ }_{2}$ films, and MC-PCL (95:5) films. As seen from FTIR spectrum of MC-PCL-F-GA peak of carbonyl stretching vibration appeared at $1703 \mathrm{~cm}^{-1}$, which ascribed to aldehyde group of GA and indicated that the crosslinking occurred [52]. The characteristic bands at 3061,1655 , and $1242 \mathrm{~cm}^{-1}$ in the spectra of $5-\mathrm{FU}$ refer to the $\mathrm{N}-\mathrm{H}$ stretching vibration, $\mathrm{C}-\mathrm{O}$ stretching vibration and C-F stretching bands, respectively. There are no significant differences between the spectra of drug loaded magnetic films and unloaded blend films. However, the band at around $1244 \mathrm{~cm}^{-1}$ in the spectrum of drug loaded magnetic films confirms the presence of the 5FU and indicates the absence of any chemical interactions between the drug and the polymer. In Figure $4 \mathrm{~b}$ the FTIR spectrum of MC-PCL-M films is shown. As can be concluded from the figure the FTIR spectra of both films are almost the same.

The X-ray diffraction patterns of pure MC and PCL are represented in Figure 5. It could be seen from Figure 5a that the spectra of pure MC film showed two peaks at $2 q=7.9^{\circ}$ and $2 \mathrm{q} \cong 20.8^{\circ}$ related to the semicrystalline structure of MC. The peak at $7.9^{\circ}$ ascribed to glucose-type crystalline order in the MC. As mentioned by Rimdusit et al. [52] the peaks at $2 \theta=9-21^{\circ}$ indicate the intermolecular structure of the MC and some authors assumed that the $2 \mathrm{q}=8^{\circ}$ peak represents the degree of cellulose modification [52,61-63]. Figure 5 shows the spectra of pure PCL film. There is a sharp peak at $2 \theta=21.9^{\circ}$ indicating highly ordered chain folding characteristics, related to the semi crystalline structure of PCL $[55,58]$. X-ray diffraction pattern of blends containing MC-PCL are given in Figure 5. According to this figure the intensity of peak at $2 \mathrm{q} \cong 21^{\circ}$ increases by increasing of the amount of PCL and the blends show more crystalline structure.

The X-ray diffraction pattern of $\mathrm{Fe}_{3} \mathrm{O}_{4}$ nanoparticles, MCPCL- $\mathrm{M}_{1}$ films, and MC-PCL(95:5) films were also investigated and presented in Figure 6a. The characteristic peaks for

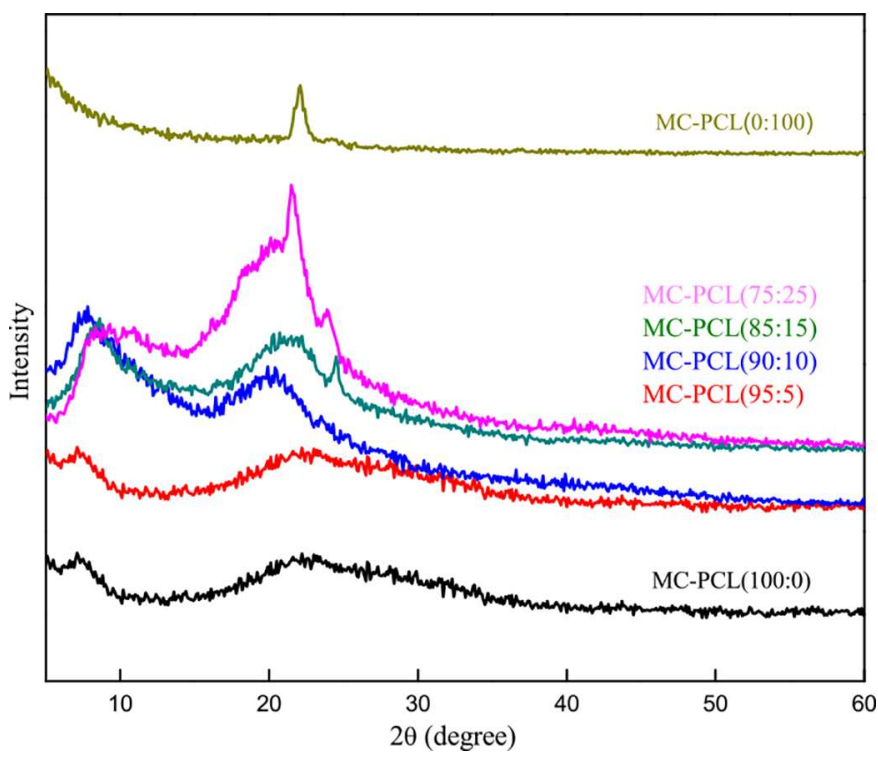

Figure 5. XRD diffraction patterns of $M C, P C L$, and $M C-P C L$ blend films.

MC-PCL-M $M_{1}$ films at $2 \theta=30.2^{\circ}, 35.5^{\circ}$, and $43.1^{\circ}$ can be attributed to the indices ( $\left(\begin{array}{lll}2 & 2 & 0\end{array}\right),\left(\begin{array}{lll}3 & 1 & 1\end{array}\right)$, and ( $\left.\begin{array}{lll}4 & 0 & 0\end{array}\right)$ of the $\mathrm{Fe}_{3} \mathrm{O}_{4}$ nanoparticles, respectively [46]. The data obtained confirmed the existence of $\mathrm{Fe}_{3} \mathrm{O}_{4}$ nanoparticles in the structure of magnetic films and showed that the crystallinity of gels increased when $\mathrm{Fe}_{3} \mathrm{O}_{4}$ nanoparticles were added. Also, Figure $6 \mathrm{~b}$ shows the X-ray diffraction pattern of MC-PCL blend along with MC-PCL-M.

The TGA analysis in which a sample loses mass with increasing temperature directly provided the information about the thermal stability and the degradation mechanism of materials. Figure 7 shows TGA waves of the MC/PCL blends and the weight loss due to the volatilization of the degradation products. It can be noticed that a slight weight loss $(\sim 3 \mathrm{wt} \%$ to $7 \mathrm{wt} \%)$ of $\mathrm{MC}$ and blends started below $100^{\circ} \mathrm{C}$ which was reported that the possible causes for the initial weight loss are probably due to moisture and high water-retention capacity of MC. The major weight loss of pure
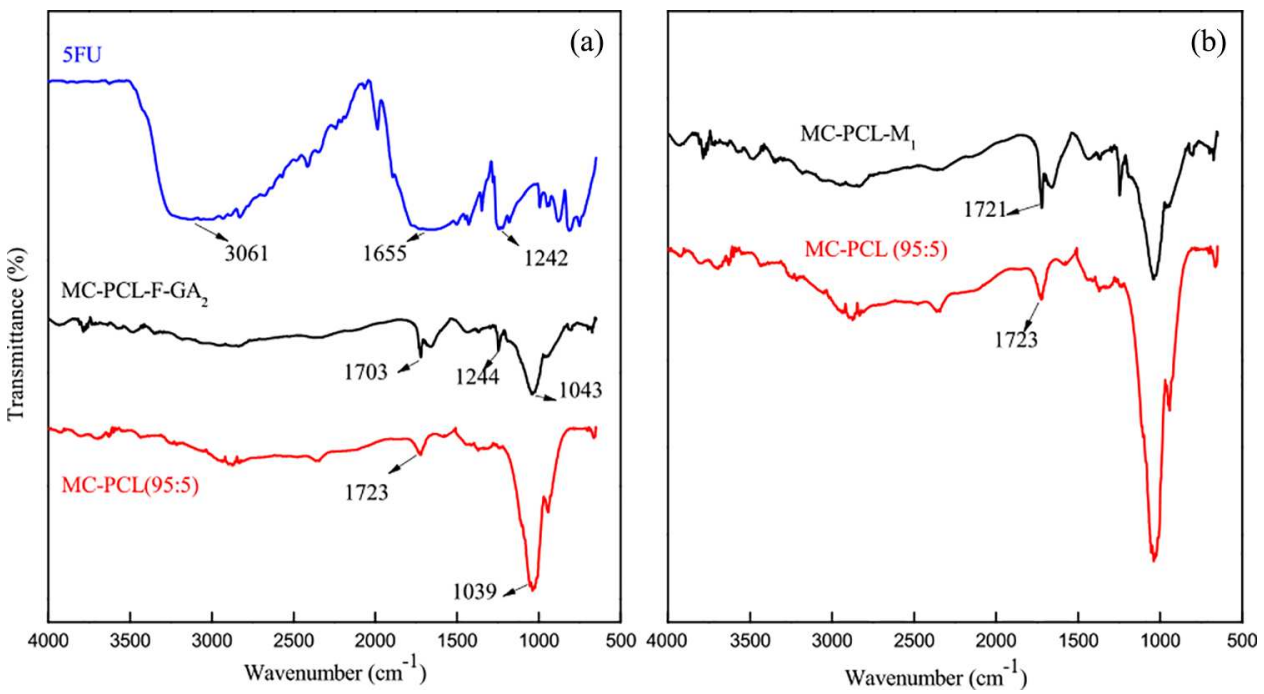

Figure 4. FTIR spectra of 5FU, MC-PCL-F-GA, MC-PCL(95/5) blend film (a) and MC-PCL(95/5) blend film and MC-PCL-M film (b) taken by ATR method. 

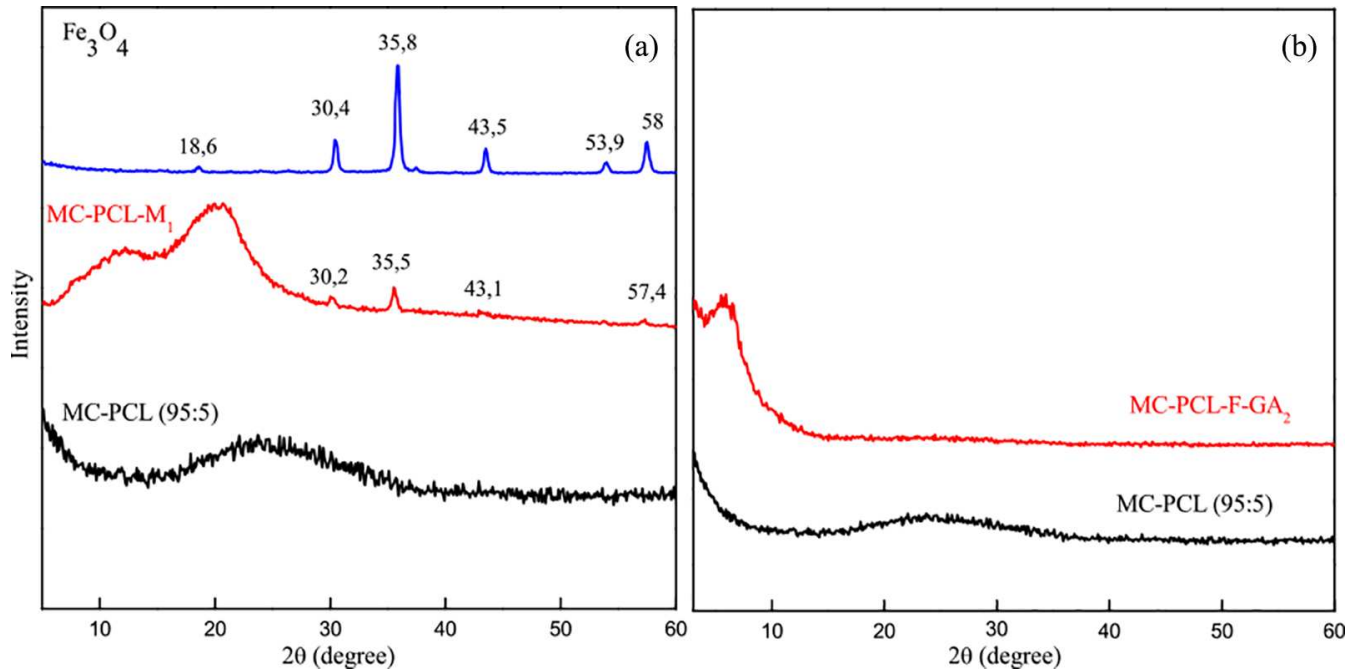

Figure 6. XRD diffraction patterns of 5 FU, MC-PCL-M 1 , MC-PCL (95/5) blend film (a) and MC-PCL (95:5) blend film, and MC-PCL-F-GA film (b).

MC film took place in the temperature range of $300-390^{\circ} \mathrm{C}$ because of the degradation of MC. All curves were almost approaching a plateau value beyond $450^{\circ} \mathrm{C}$, as mainly char residue remained. The TGA curve of PCL displays one main degradation with an inflection point at around $420^{\circ} \mathrm{C}$. The temperature corresponding to $5 \%$ weight loss $\left(\mathrm{T}_{5 \%}\right)$ deduced from Figure $8 . \mathrm{T}_{5 \%}$ of the MC-PCL blends increases as the concentration of PCL increases. MC shows lower thermal stability than PCL and the addition of PCL improves the thermal stability of blends. The temperature at the maximum rate of weight loss is called $\mathrm{T}_{\max }$ and determined by the derivative thermogravimetry (DTG) curve. The DTG curves for pure MC, PCL and blends are shown in Figure 8. $\mathrm{T}_{\max }$ of blends is located between those of pure MC and PCL. The $\mathrm{T}_{\max }$ values increase by the concentration of PCL in blends as can be seen from Figure 8.

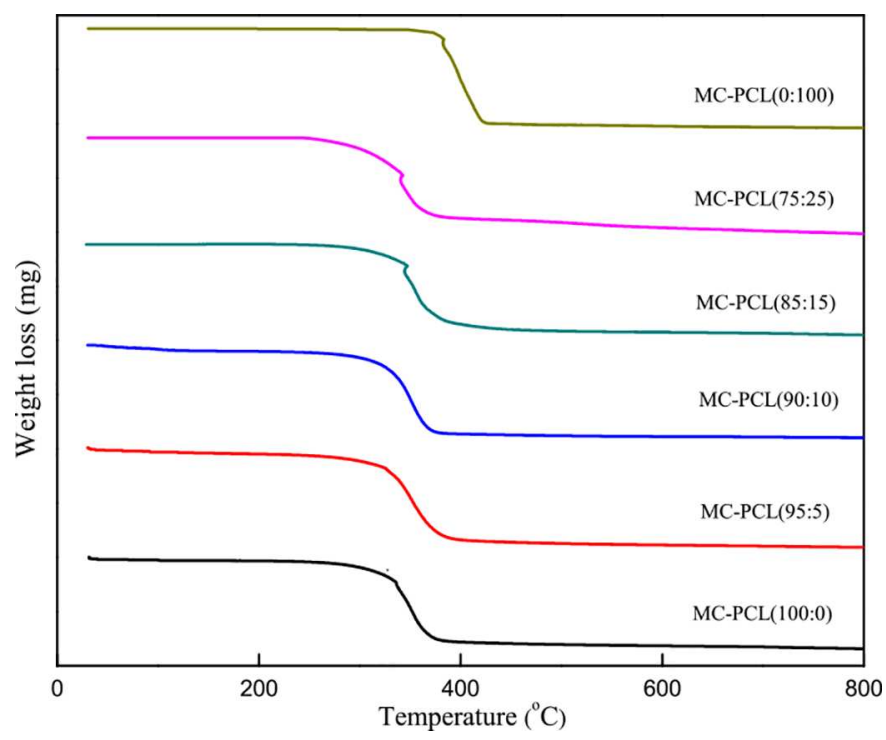

Figure 7. Thermogravimetric curves for pure $\mathrm{MC}, \mathrm{PCL}$ and $\mathrm{MC}-\mathrm{PCL}$ blends at a heating rate of $20^{\circ} \mathrm{C} / \mathrm{min}$.

\subsection{SEM and SEM-EDS analysis}

Table 1 shows the results of the analysis of superficial surface by semiquantitative SEM-EDS for the magnetic MC-PCL gels with different compositions $(1 \%, 3 \%$ and $6 \%)$ of $\mathrm{Fe}_{3} \mathrm{O}_{4}$ nanoparticles. As shown in Table 1, the elemental compositions of

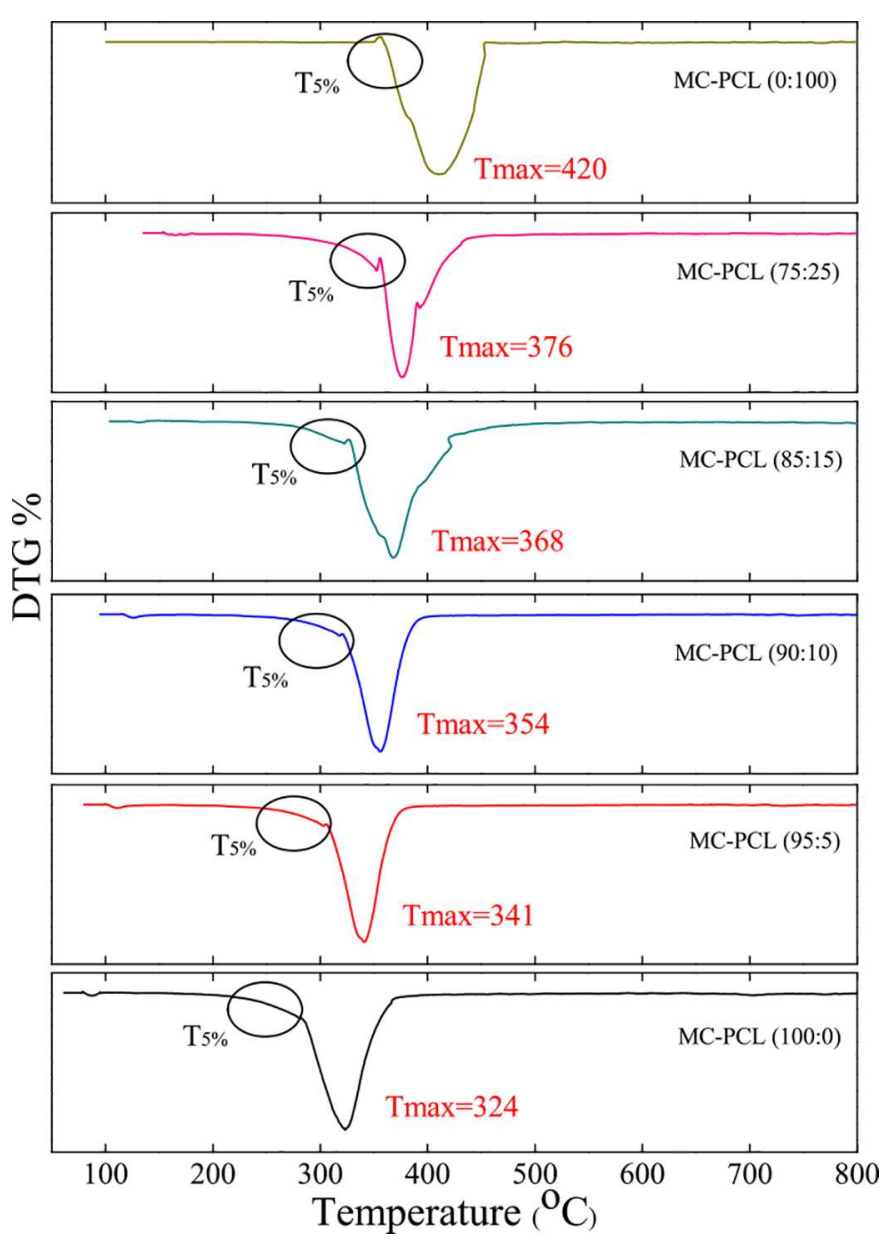

Figure 8. DTG curves for pure $M C, P C L$ and $M C-P C L$ blends at a heating rate of $20^{\circ} \mathrm{C} / \mathrm{min}$. 
Table 1. SEM-EDS analysis of the elemental compositions ( $C, O$ and $\mathrm{Fe}$ ) of MC-PCL-M, MC-PCL-M $M_{3}$ and MC-PCL-M $M_{6}$ films.

\begin{tabular}{lcccc}
\hline Gel films code & $\mathrm{C} \%$ & $\mathrm{O} \%$ & $\mathrm{C} / 0$ & $\mathrm{Fe} \%$ \\
\hline MC-PCL-M & 62.65 & 36.30 & 1.72 & 1.05 \\
MC-PCL-M & 61.95 & 34.51 & 1.79 & 3.53 \\
MC-PCL-M $_{6}$ & 60.92 & 34.12 & 1.78 & 4.96 \\
\hline
\end{tabular}

three samples include the same portion of $\mathrm{C} / \mathrm{O}(1.7)$ and the differences between these samples are in the varying compositions of $\mathrm{Fe}$. The compositions of $\mathrm{Fe}$ are $1.05 \%, 3.53 \%$, and $4.96 \%$ for MC-PCL-M ${ }_{1}$, MC-PCL-M ${ }_{3}$, and MC-PCL-M $\mathrm{M}_{6}$ respectively. The Fe composition $(1.05 \%)$ for MC-PCL-M ${ }_{1}$ matched with their corresponding real composition $(1 \%)$ of the constituted component with acceptable deviation. Element composition values for the MC-PCL-M $\mathrm{M}_{3}$ and MC-PCL-M samples were different from real values and the highest difference is observed for the MC-PCL-M $\mathrm{M}_{6}$ sample. For MC-PCL$\mathrm{M}_{1}$ sample, it was concluded that the $\mathrm{Fe}_{3} \mathrm{O}_{4}$ nanoparticles were fairly uniformly distributed in the polymeric matrix and deviation from homogeneously distribution were observed for other samples especially for the MC-PCL-M 6 .

As shown in Figure 9a the results of superficial surface EDS mapping confirm that the Fe element in MC-PCL-M $\mathrm{M}_{1}$ was homogeneously distributed on the polymeric matrix [10]. These results indicated that the $\mathrm{Fe}_{3} \mathrm{O}_{4}$ nanoparticles were well mixed in the preparation of polymer composite structure. As shown in Figure 9a, Fe element of MC-PCL-M 3 slightly deflected from

(a)
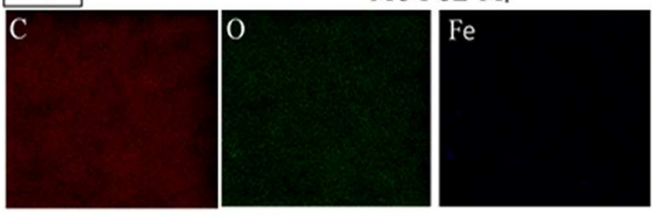

MC-PCL-M
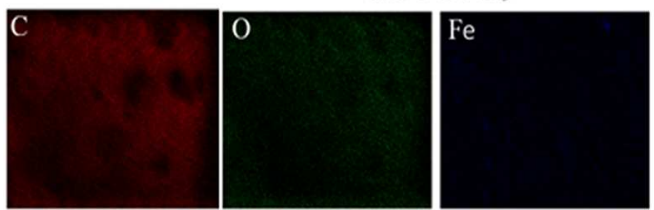

MC-PCL-M ${ }_{6}$
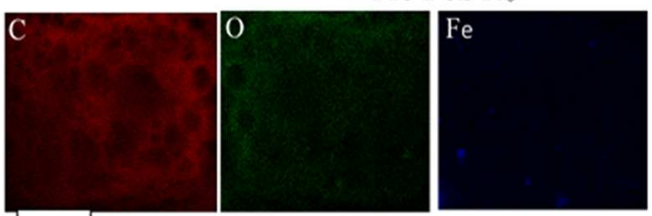

(b)
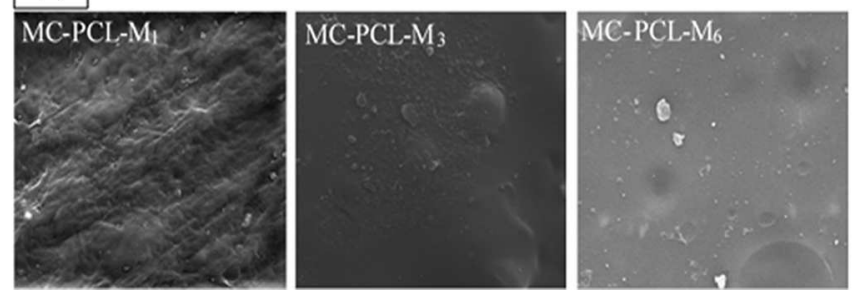

Figure 9. (a)Results of the EDS mapping of the $\mathrm{C}, \mathrm{O}$ and Fe elements on the superficial surfaces of MC-PCL-M films; (b) SEM micrographs of the MC-PCL-M MC-PCL-M $\mathrm{M}_{3}$, and MC-PCL-M 6 hydrogels. homogeneously distribution and some aggregation were appeared in the EDS mapping image. For $\mathrm{MC}-\mathrm{PCL}_{6}$ sample deviation from homogeneously distribution is more and the number of aggregation spot increase through the polymer composite structure. These results help to take into account that increases in the concentration of the $\mathrm{Fe}_{3} \mathrm{O}_{4}$ nanoparticles causes deviation from the homogeneously distribution.

The morphology of the MC-PCL-M hydrogels was analyzed by scanning electron microscopy. As shown in Figure 9b, there are no big differences between the SEM images of hydrogels. The morphology of the samples showed almost smooth and uniform surfaces. However, SEM image of MC-PCL-M ${ }_{1}$ changed to dense structures in MC-PCL-M $\mathrm{M}_{3}$ and MC-PCL-M related to the increase in concentration of $\mathrm{Fe}_{3} \mathrm{O}_{4}$ nanoparticles. The bulks of $\mathrm{Fe}_{3} \mathrm{O}_{4}$ nanoparticles were observed on the surface of MC-PCL- $\mathrm{M}_{3}$ and MC-PCL-M . $_{\text {. }}$

\subsection{Analysis of magnetization properties}

The MC-PCL-M hydrogel films displayed magnetic properties of the involved $\mathrm{Fe}_{3} \mathrm{O}_{4}$ nanoparticles. Figure 10 shows the magnetization curves of the MC-PCL- $\mathrm{M}_{1,3,6}$ hydrogel films measured at $300 \mathrm{~K}$. The magnetization curves showed that the MC-PCL-M $\mathrm{M}_{1,3,6}$ hydrogels were superparamagnetic with no hysteresis and coercivity at room temperature. This characteristic property belongs to superparamagnetic nanoparticles that the thermal fluctuations are sufficient to prevail the anisotropic energy barrier [64,65].

The saturation magnetization values for MC-PCL-M $\mathrm{M}_{1}$, MC-PCL- $\mathrm{M}_{3}$, and MC-PCL-M $\mathrm{M}_{6}$ were found as $1.02,2.07$, and $3.78 \mathrm{emu} / \mathrm{g}$, respectively, clearly dependent on the values of $\mathrm{Fe}_{3} \mathrm{O}_{4}$ nanoparticles incorporation in the hydrogel structure [64]. We can see that the saturation magnetization (Ms) of the samples increases when the concentration of magnetite increases in the polymeric matrices. This result is suggesting that magnetic intensity of the hydrogels can be easily arranged by altering the weight ratio of $\mathrm{Fe}_{3} \mathrm{O}_{4}$ nanoparticles [66]. This

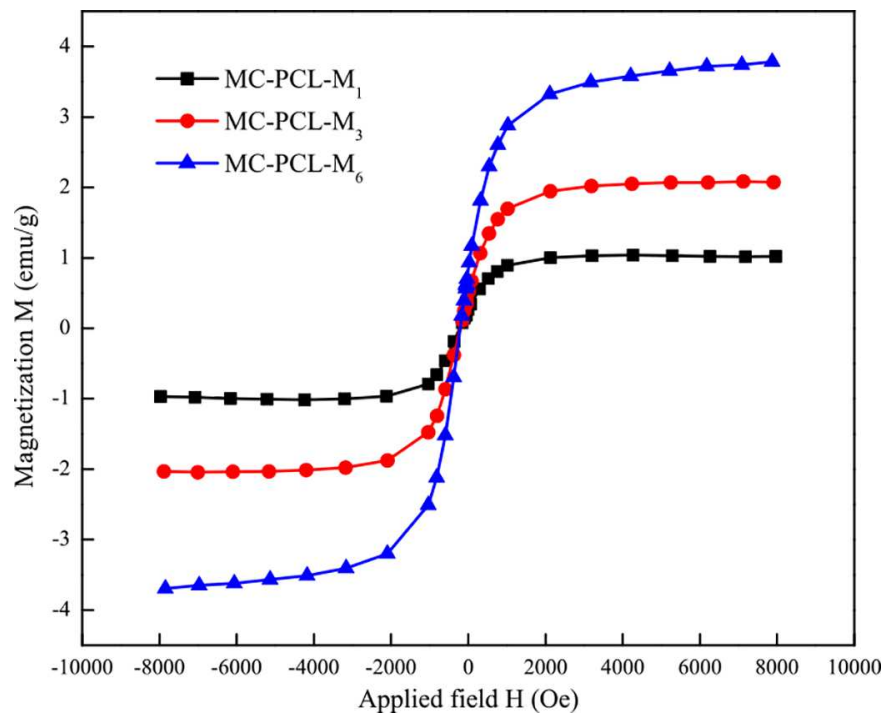

Figure 10. Magnetic hysteresis loops of the MC-PCL-M,$M C-P C L-M_{3}$, and MC$\mathrm{PCL}-\mathrm{M}_{6}$ hydrogels at $300^{\circ} \mathrm{K}$. 
feature can be very important for practical applications because the drug release properties of hydrogels may be affected by their magnetic intensity under a certain magnetic field, displaying the feasibility of controlled drug release to specific target.

\subsection{Swelling properties}

The ESV of synthesized gel films (MC-PCL-F-GA) and discs

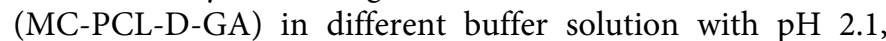
4.0, 7.2, and 10.0 are shown in Figures 11 and 12. Figure 11 shows the swelling behaviors of crosslinked films, which indicate that the films are sensitive to the amount of crosslinker and $\mathrm{pH}$ of medium. The increasing of the content of crosslinker up to $2 \%$ has positive effect on the swelling value. Furthermore, films showed the best swelling at $\mathrm{pH}=7.2$. The swelling behavior of crosslinked discs was seen in Figure 12. Furthermore, the discs are sensitive to $\mathrm{pH}=7.2$ but they have low sensitivity to the content of crosslinker and the best ESV has been shown at $4 \%$ crosslinker content. As shown in Figures 11 and 12, synthesized (MC-PCL) hydrogels had better ESVs in the form of discs in comparison of films. The difference in the swelling values of films and discs may relate to the preparation process and explain by the fact that discs had sufficient time to crosslinking during the preparation by $24 \mathrm{~h}$ incubation in the water bath. Consequently discs had better cross-linked network structure and better swelling values. In comparison to the films that started to the drying immediately after the mixing of the polymers and adding GA as crosslinking agent.

\subsection{Drug release measurement}

The drug release from drug loaded films was studied in two different buffer solutions of $\mathrm{pH} 2.1$ and 7.2. The ionic strength of buffer solutions was adjusted at $0.08 \mathrm{M}$, by adding an appropriate amount of $\mathrm{NaCl}$. The influence of $\mathrm{pH}$ on the drug

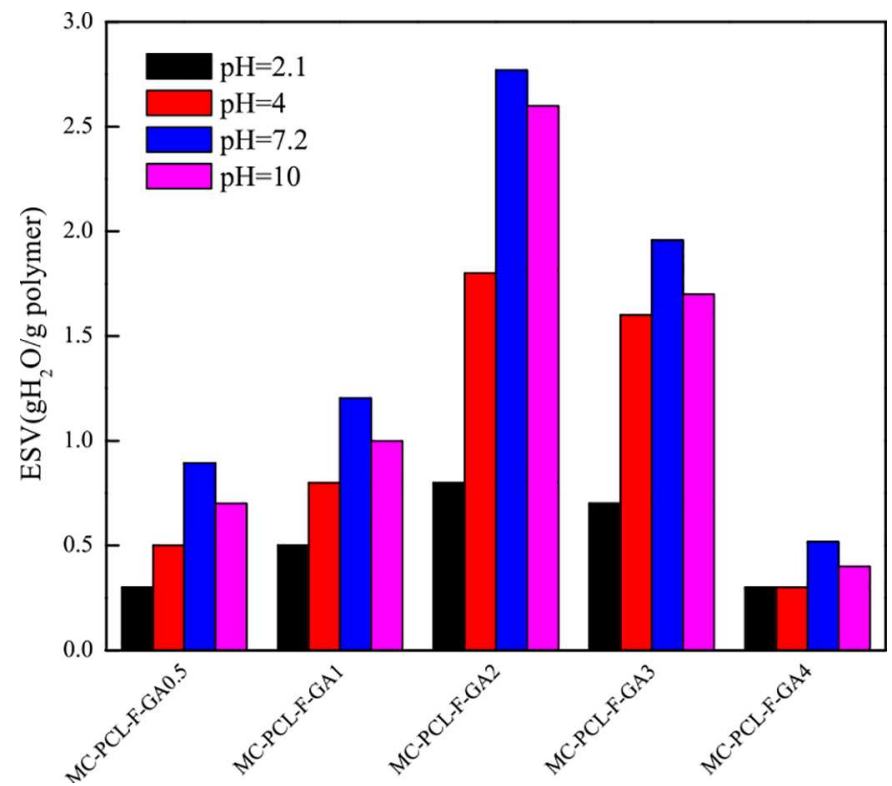

Figure 11. Equilibrium swelling values (ESV) of MC-PCL-F-GA $A_{0.5-4.0}$ films (MC) PCL(95:5), F: film, GA concentrations as $0.5 \%, 1 \%, 2 \%, 3 \%$, and $4 \%$ ) in buffer solutions with different $\mathrm{pH}$ and temperature of $37^{\circ} \mathrm{C}$. release profile was investigated and the results were shown for the loaded films and discs in Figure 13. The drug release from loaded films was very sensitive to the $\mathrm{pH}$ of the medium. The amount of drug release was higher at $\mathrm{pH}=7.2$ than at $\mathrm{pH}=2.1$ and it reaches up to $80 \%$ of release in $6 \mathrm{~h}$. The results were consistent with the value of water swelling equilibrium value for the synthesized films. The drug release from loaded discs was sensitive to the $\mathrm{pH}$ and the amount of drug release was higher at $\mathrm{pH}=7.2$ than $\mathrm{pH}=2.1$ and it reaches up to $60 \%$ of release in $6 \mathrm{~h}$.

However, all drug loaded films and discs show a biphasic release mechanism at the initial hours of drug release experiment and a prolonged releases manner at continue (Figure 13). The burst release of the drug is belong to reveal of the drug molecules from the surface layer of the scaffolds and

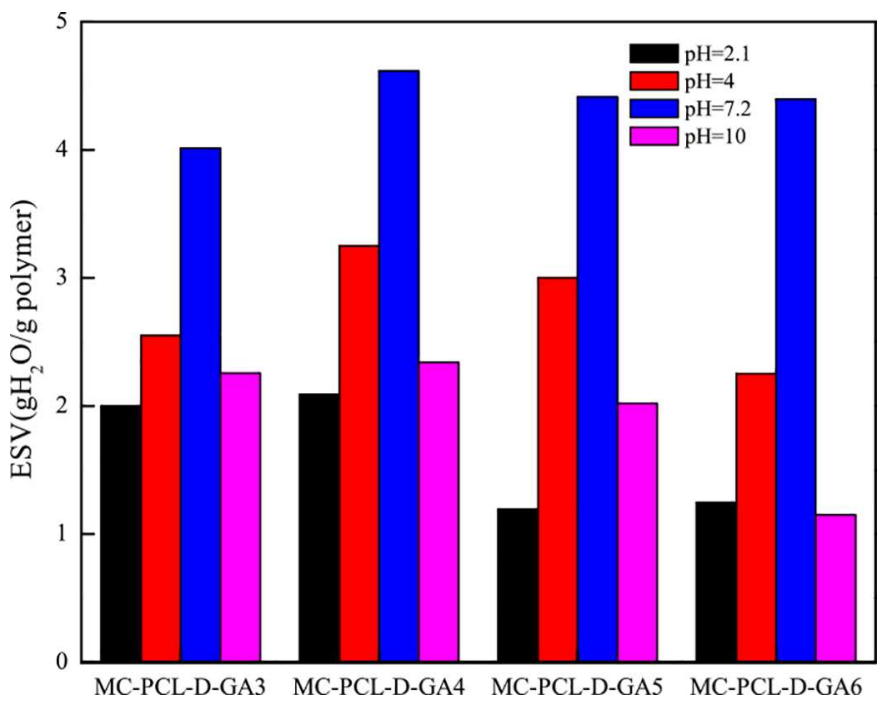

Figure 12. Equilibrium swelling values (ESV) of MC-PCL-D-GA ${ }_{3-6}$ discs (MC/PCL (95:5), D:disc, GA concentration 3\%, 4\%,5\%, and $6 \%$ ) in buffer solutions with different $\mathrm{pH}$ and temperature of $37^{\circ} \mathrm{C}$

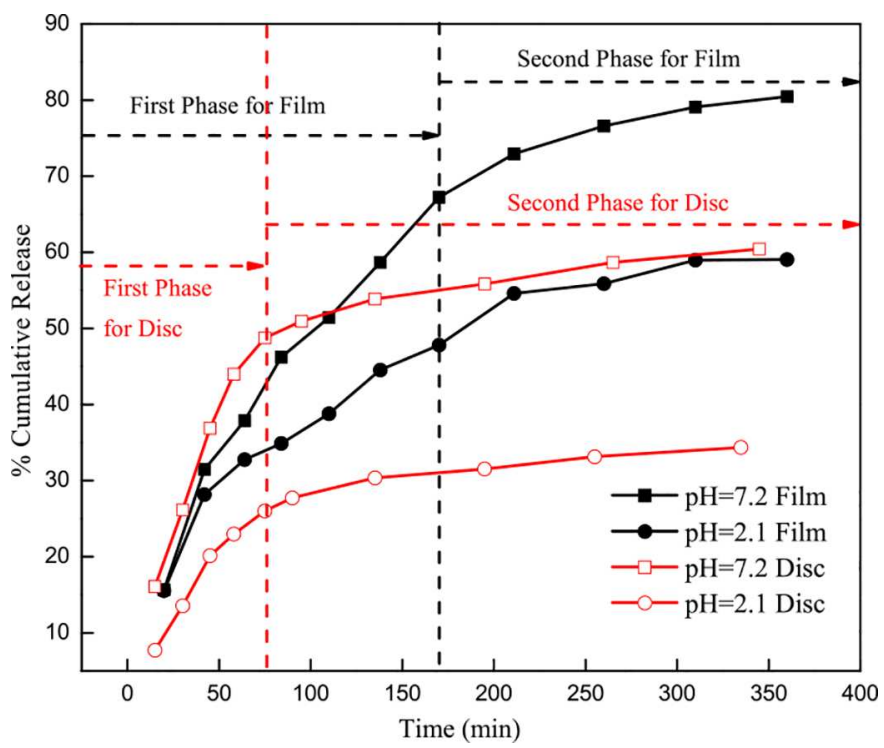

Figure 13. Drug release profile of MC-PCL-F-GA film and MC-PCL-D-GA $A_{4}$ disc at different $\mathrm{pH}$ and temperature of $37^{\circ} \mathrm{C}$ 
progressively dissolved when they come in contact with the release medium [67]. The first phase including quick release of the drug from the polymeric matrix happened within $(0-$ $70 \mathrm{~min}$ ) and changed to gently release after this period as the second phase (70-340 min) for discs. Furthermore, in the case of films the first phase prolonged almost up to $170 \mathrm{~min}$ and after this period the release profile changed to gently release as second phase (170-340 min). Meanwhile, the films have extended surface area in comparison with gel discs, the first phase for drug release is longer than drug release for gel discs.

The Korsmeyer-Peppas model successfully was used for reproducing of the experimental data of the drug release profile in phosphate buffer solution, which gains an insight into its release kinetics. The factor $\mathrm{n}$ was determined and is shown in Table 2 for disc gels from the slopes of the fit curves as $0.7793,0.7501$ and $\mathrm{R}^{2}=0.9889,0.9984$ for $\mathrm{pH}=2.1$ and $\mathrm{pH}$ $=7.2$, respectively. Furthermore, the values of $\mathrm{n}$ were determined for gel films from the slopes of the fit curves as $0.6060,0.8620$ and $\mathrm{R}^{2}=0.9914,0.9969$ for $\mathrm{pH}=2.1$ and $\mathrm{pH}$ $=7.2$, respectively. These results confirm the non-Fickian transport of drug release and attributes to the combination of diffusion as well as swelling controlled release mechanism $[68,69]$. That means the release profile was not controlled just by the swelling phenomena. Although the discs had the grater ESV values, in the case of release from the films, it seems the diffusion phenomena overcome to the swelling phenomena and the cumulative release values were greater than discs. As mentioned before, the films had extended surface area in comparison of the discs, consequently had greater diffusion and longer first phase release and finally greater percent cumulative release values during the drug release experiment.

\subsection{Drug release measurement under magnetic field}

As mentioned previously, it is common in the release systems that the releasing rate in the first minutes is very fast and then turns to a relative gently release. This initial burst in the release profile possibly belongs to the quick diffusion of drugs from the outer layer of the gels. Prolongation of the release time is an important factor in drug therapy because it can enhance the efficiency of the drug. Magnetic field sensitive gels are good vehicles to control of release from polymeric scaffolds and overcome the initial burst of release [70]. The effect of the external magnetic field on the drug release profile from the magnetic MC/PCL gel films (MC-PCL-M $\mathrm{M}_{1}$ ) was presented in Figure 14a. The amount of released drug decreased under external magnetic field of $24.2 \mathrm{mT}$. Furthermore, the effect of concentration of $\mathrm{Fe}_{3} \mathrm{O}_{4}$ nanoparticles on release profile was also investigated. For this aim, five typical samples including series of magnetic gel films (MC-PCL-M ${ }_{1-6}$ ) with different concentration of $(1 \%, 2 \%, 3 \%, 4 \%$, and $6 \%) \mathrm{Fe}_{3} \mathrm{O}_{4}$ nanoparticles, were chosen and the drug release profiles were measured

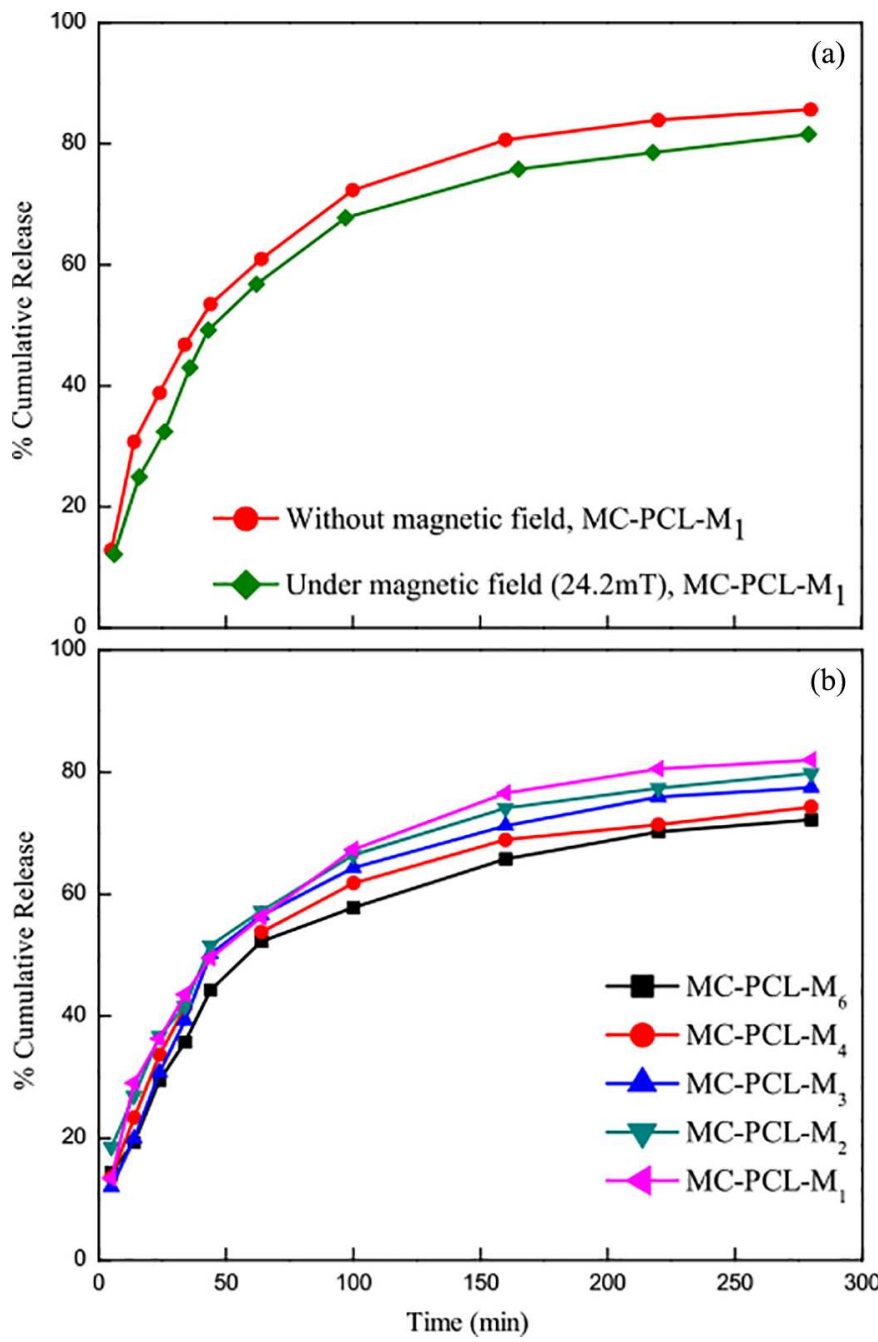

Figure 14. Effect of external magnetic field on drug release profile of drug loaded MC-PCL-M $\mathrm{M}_{1}$ without and under magnetic field of $24.2 \mathrm{mT}$ at $\mathrm{pH}=7.2$ and temperature of $37^{\circ} \mathrm{C}$ (a). Drug release profile of MC-PCL-M $\mathrm{M}_{1-6}$ films under magnetic field (24.2 mT), $\mathrm{pH}=7.2$ and temperature of $37^{\circ} \mathrm{C}(\mathrm{b})$.

over time as presented in Figure 14b. The amount of the drug release and the releasing rate of the five samples decreased after applying an external magnetic field $(24.2 \mathrm{mT})$ with the increasing of the nanoparticle concentration. These results show the concentration of $\mathrm{Fe}_{3} \mathrm{O}_{4}$ nanoparticles has an obvious influence on the release properties of magnetic gel films. Furthermore, as mentioned for the synthesized films, the first phase release took place within (0-170) and after this period the release profile changed to gently release as second phase.

This behavior can be explained by the presence of attractive interaction between $\mathrm{Fe}_{3} \mathrm{O}_{4}$ nanoparticles and drug. Furthermore, the magnetic moments can be aligned together in the presence of external magnetic field and led to accumulate of $\mathrm{Fe}_{3} \mathrm{O}_{4}$ nanoparticles and decrease in pore size of magnetic hydrogels subsequently decrease in diffusion of drug from

Table 2. Diffusional exponent (n), release constant (In K), and correlation coefficient $\left(R^{2}\right)$ of drug loaded $M C-P C L$ hydrogels in buffer solutions.

\begin{tabular}{|c|c|c|c|c|c|c|}
\hline \multirow[b]{2}{*}{ Gel films code } & \multicolumn{2}{|c|}{$\mathrm{n}$} & \multicolumn{2}{|c|}{$\ln \mathrm{K}$} & \multicolumn{2}{|c|}{$\mathrm{R}^{2}$} \\
\hline & $\mathrm{pH}=2.1$ & $\mathrm{pH}=7.2$ & $\mathrm{pH}=2.1$ & $\mathrm{pH}=7.2$ & $\mathrm{pH}=2.1$ & $\mathrm{pH}=7.2$ \\
\hline MC-PCL-D-GA ${ }_{2}$ (disc) & 0.7793 & 0.7501 & 3.5802 & 3.3645 & 0.9889 & 0.9984 \\
\hline MC-PCL-F-GA $($ film) & 0.6060 & 0.8620 & 3.2449 & 4.3471 & 0.9914 & 0.9969 \\
\hline
\end{tabular}


polymeric matrix. On the other hand, the aggregation of $\mathrm{Fe}_{3} \mathrm{O}_{4}$ nanoparticles causes the formation of magnetic sensitive walls in the structure of gel films and restricts the permeability of magnetic hydrogels (close configuration). This restriction causes to retard the drug release under magnetic field $[71,72]$. This behavior is very similar to those reported in the literature [46,73-75]. However, there are different results for some temperature sensitive polymers and increasing in drug release has been reported for these kinds of magnetic sensitive systems. This behavior may explain by oscillation of magnetic moments and producing of heat under magnetic field and subsequently enlarge the nanostructure of the polymeric matrix to make porous channels that cause increasing drug releases easily [76,77]. As $\mathrm{Fe}_{3} \mathrm{O}_{4}$ nanoparticles were physically dispersed throughout the polymeric matrix in hydrogels, this hydrogels act as magnetic label for the drugs and lead the drug to the targeted area of treatment under external magnetic field. This behavior allows for a tissue-specific release of drugs consequently reduces the side effects of the drugs to other areas of the body [66].

\section{Conclusions}

MC-PCL hydrogels have been prepared and characterized by FTIR, XRD, TGA, SEM-EDS, and VSM analysis. FTIR and XRD spectra confirmed the uniform mixing of the polymers and functional groups for both of the polymers identified successfully. Additionally, FTIR spectra indicated crosslinking process between polymers. According to the TGA analysis, the addition of PCL to MC improves the thermal stability of blends. SEM-EDS analysis indicated that the MC and PCL polymers were well mixed in the preparation of hydrogels. Furthermore, $\mathrm{Fe}_{3} \mathrm{O}_{4}$ nanoparticles were homogeneously distributed at low concentration on the polymeric matrix. The swelling studies of the MC-PCL gel films represents the positive effect of the increasing amount of the crosslinker up to $2 \%$ on the ESV at $\mathrm{pH}=7.2$. Similarly, the best ESV was found at $4 \%$ of crosslinker content and $\mathrm{pH}=7.2$ for discs. $5-\mathrm{FU}$, as model drug, was loaded in hydrogel films and discs and the release behavior of drug was investigated. The release profiles presented $\mathrm{pH}$-dependent behavior with high releasing at $\mathrm{pH}=7.2$ for both films and discs. The release profiles indicated non-Fickian type diffusion for drug release. The decreasing trend in the amount of released drug was observed for magnetic MC-PCL hydrogels under external magnetic field. Furthermore, decreasing in release was sensitive to concentration of $\mathrm{Fe}_{3} \mathrm{O}_{4}$ nanoparticles. These behaviors allow for design of magneto sensitive and tissue-specific release of drugs that reduces side effects of the cancer drugs to other areas of the body. Although drug release studies of 5-FU with different formulation have been reported in the literature, as far as we know there haven't been any reports yet, concerning drug release investigation of 5-FU within MC-PCL hydrogels and $\mathrm{Fe}_{3} \mathrm{O}_{4}$ nanoparticles.

\section{Funding}

This work was supported by Scientific Research Projects (BAP) Coordination Unit of Istanbul University (project number, 25775).

\section{References}

[1] Tang, Y.; Wang, X.; Li, Y.; Lei, M.; Du, Y.; Kennedy, J. F.; Knill, C. J. Carbohydr. Polym. 2010, 82, 833.

[2] Chatterjee, T.; Nakatani, A. I.; Adden, R.; Brackhagen, M.; Redwine, D.; Shen, H.; Li, Y.; Wilson, T.; Sammler, R. L. Biomacromolecules 2012, 13, 3355.

[3] Takahashi, M.; Shimazaki, M.; Yamamoto, J. J. Polym. Sci. B: Polym. Phys. 2001, 39, 91.

[4] Xu, Y.; Li, L. Polymer 2005, 46, 7410.

[5] Xu, Y.; Wang, C.; Tam, K. C.; Li, L. Langmuir 2004, 20, 646.

[6] Kuang, Q.; Cheng, G.; Zhao, J.; Li, Y. J. Appl. Polym. Sci. 2006, 100, 4120.

[7] Kundu, P. P.; Kundu, M.; Sinha, M.; Choe, S. Chattopadhayay, D. Carbohydr. Polym. 2003, 51, 57.

[8] Nikjoo, D.; Aroguz, A. J. Macromol. Sci. Pure. 2013, 50, 1007.

[9] Xu, Y.; Wang, C.; Stark, N. M.; Cai, Z.; Chu, F. Carbohydr. Polym. 2012, 88, 422 .

[10] Liang, H. F.; Hong, M. H.; Ho, R. M.; Chung, C. K.; Lin, Y. H.; Chen, C. H. Biomacromol. 2004, 5, 1917.

[11] Babu, V. R.; Sairam, M.; Hosamani, K. M.; Aminabhavi, T. M. Carbohydr. Polym. 2007, 69, 241.

[12] Liu, W.; Zhang, B.; Lu, W. W.; Li, X.; Zhu, D.; Yao, K. D. Biomaterials 2004, 25, 3005.

[13] Gupta, D.; Tato, C. H.; Shoichet, M. S. Biomaterials 2006, 27, 2370.

[14] Natta, F. J. V.; Hill, J. W.; Carothers, W. H. Am. Chem. Soc. 1934, 56, 455.

[15] Woodruff, M. A.; Hutmacher, D. W. Prog. Polym. Sci. 2010, 35, 1217.

[16] Braganca, F. C.; Rasa, D. S. Polym. Adv. Technol. 2003, 14, 669.

[17] Li, B. B.; Wu, Y. T.; Liu, M. H.; Esker, A. R. Langmuir 2006, 22, 4902.

[18] Miola, C.; Hamaide, T.; Spitz, R. Polymer 1997, 38, 5667.

[19] Yamashita, K.; Kikkawa, Y.; Kurokawa, K.; Doi, Y. Biomacromolecules 2005, 6, 850 .

[20] Vert, M. J. Mater. Sci. Mater. Med. 2009, 20, 437.

[21] Muller, R. J.; Kleeberg, I.; Deckwer, W. D. J. Biotechnol. 2001, 86, 87.

[22] Olhoft, G. V.; Eldred, N. R.; Koleske, J. V. U.S. Patent No. 3,642,507, 1972.

[23] Kusumi, R.; Inoue, Y.; Shirakawa, M.; Miyashita, Y.; Nishio, Y. Cellulose 2008, 15, 1.

[24] Nishio, Y.; Matsuda, K.; Miyashita, Y.; Kimura, N.; Suzuki, H. Cellulose $1997,4,131$.

[25] Hubbell, D. S.; Cooper, S. L. J. Appl. Polym. Sci. 1977, 21, 3035.

[26] Hatakeyama, H.; Yoshida, T.; Hatakeyama, T. J. Therm. Anal. Calorim. 2000, 59, 157.

[27] Rosa, D. S.; Guedes, C. G. F.; Bardi, M. A. G. Polym. Test. 2007, 26, 209.

[28] Zhou, X. S.; Huang, Y. J. Appl. Polym. Sci. 2004, 93, 550.

[29] Boumail, A.; Salmieri, S.; Klimas, E.; Tawema, P. O.; Bouchard, J.; Lacroix, M. J. Agric. Food Chem. 2013, 61, 811.

[30] Yang, A. L.; Wu, R. J.; Zhu, P. F. J. Appl. Polym. Sci. 2001, 81, 3117.

[31] Gassner, F.; Owen, A. J. Polymer 1994, 35, 2233.

[32] Aroguz, A. Z.; Baysal, K.; Tasdelen, B.; Baysal, B. M. J. Appl. Polym. Sci. 2011, 119, 2885.

[33] Giannola, L.; De Caro, V.; Giandalia, G.; Siragusa, M. G.; Paderni, C.; Campisi, G.; Florena, A. M. Curr. Drug Deli. 2010, 7, 109.

[34] Loven, K.; Stein, L.; Furst, K.; Levy, S. Clin. Ther. 2002, 24, 990.

[35] Aprahamian, M.; Michel, C.; Humbert, W.; Devissaguet, J. P.; Damge, C. Biol. Cell. 1987, 61, 69.

[36] Bounous, G.; Pageau, R.; Regoli, D. Int. J. Clin. Pharmacol. Biopharm. 1978, 16, 519.

[37] Shabbear, S.; Ramanamurthy, S.; Ramanamurthy, K. V. Int. J. Res. Pharm. Chem. 2012, 2, 7.

[38] Woolfson, A. D.; Mc Cafferty, D. F.; Mc Carron, P. A.; Price, J. H. J. Control Release 1995 35, 676.

[39] Chandrashekar, N. S.; Prasanth, V. V. Asian Pac. J. Cancer Prev. 2008, 9, 437.

[40] Sivabalan, M.; Punitha Vani, T.; Reddy, P.; Jose, A.; Nigila, G. Pharmacie Globale (IJCP) 2011, $1,1$.

[41] Ozbas, Z.; Gurdag, G. J. Appl. Polym. Sci. 2015, 132, 1. 
[42] Rao, K. M.; Mallikarjuna, B.; Rao, K. S. V. K.; Sudhakar, K.; Rao, K. C.; Subha, M. C. S. Int. J. Polymer. Mater. Polym. Biomater. 2013, 62, 565.

[43] El-Sherbiny, I. M.; Harding, D. R. K.; Abdel-Barey, E. M. Int. J. Polymer. Mater. Polym. Biomater. 2006, 55, 789.

[44] Anirudhan, T. S.; Binusreejayan; Rejeena, S. R. Int. J. Polym. Mater. Polym. Biomater. 2014, 63, 539.

[45] Perrin, D. D.; Dempsey, B. Buffers for $p H$ and Metal Ion Control, 1st edn.; Chapman and Hall, London, 1974.

[46] Mahdavinia, G. R.; Rahmani, Z.; Karami, S.; Pourjavadi, A.; J. Biomat. Sci. Polym. Ed. 2014, 25, 1891.

[47] Kennedy, S. K.; Walker, W.; Forslund, B. Environ. Forensics 2002, 3, 131.

[48] Sarmad, S.; Yenici, G.; Gurkan, K.; Keceli, G.; Gurdag, G. Smart Mater. Struct. 2013, 22, 055010.

[49] Korsmeyer, R. W.; Gurny, R.; Doelker, E.; Buri, P.; Peppas, N. A. Int. J. Pharm. 1983, 15, 25

[50] Dash, S.; Murthy, P. N.; Nath, L.; Chowdhury, P. Acta Pol. Pharm. 2010, 67, 217.

[51] Peppas, N. A.; Bures, P.; Leobandung, W.; Ichikawa, H. Eur. J. Pharm. Biopharm. 2000, 50, 27.

[52] Rimdusit, S.; Jingjid, S.; Damrongsakkul, S.; Tiptipakorn, S.; Takeichi, T. Carbohydr. Polym. 2008, 72, 444.

[53] Wang, X. L.; Yang, K. K.; Wang, Y. Z.; Wang, D. Y.; Yang, Z. Acta Mater. 2004, 52, 4899.

[54] Siong, K.; Amari, N. F.; Yuan, T. C.; Radiman, S.; Yahaya, R.; Samudi, M. Sains Malaysiana 2013, 42, 167.

[55] Elzubair, A.; Elias, C. N.; Suarez, J. M.; Lopes, H. P.; Vieira, M. V. B.; J. Dent. 2013, 34, 784.

[56] Elzein, T.; Brogly, M.; Schultz, J. Polymer 2003, 44, 3649.

[57] Doustgani, A.; Vasheghani- Farahani, E.; Soleimani, M.; HashemiNajafabadi, S. World Acad. Sci. Eng. Technol. 2012, 62, 18

[58] Liau, C. P.; Ahmad, M. B.; Shameli, K.; Yunus, W. N.; Ibrahim, N. A.; Zainuddin, N.; Then, Y. Y. Sci. World J. 2014, 2014, 572726.
[59] Allard, D.; Prudhomme, R. E. J. Appl. Polym. Sci. 1982, 27, 559.

[60] Kuo, S. W.; Huang, C. F.; Chang, F. C. J. Polym. Sci. Polym. Phys. 2001, 39, 1348

[61] Filho, G. R.; Assunção, R. M. N.; Vieira, J. G.; Meireles, C. S.; Cerqueira, D. A.; Barud, H. S.; Ribeiro, S. J. L.; Messaddeq, Y. Polym. Degrad. Stabil. 2007, 92, 205.

[62] Rangelova, N.; Radev, L.; Nenkova, S.; Miranda Salvado, I. M.; Vas Fernandes, M. H.; Herzog, M. Europ. J. Chem. 2011, 9, 112.

[63] Pinotti, A.; Martino, M. N. G.; Zaritzky, N. E. Food Hydrocolloids 2007, 21, 66

[64] Tan, S. T.; Wendorff, J. H.; Pietzonka, C.; Jia, Z. H.; Wang, G. Q Chem. Phys. Chem. 2005, 6, 1461.

[65] Mincheva, R.; Stoilova, O.; Penchev, H.; Ruskov, T.; Spirov, I.; Manolova, N.; Rashkov, I. Eur. Polym. J. 2008, 44, 615.

[66] Wang, L.; Wang, M.; Topham, P. D.; Huang, Y. RSC Adv. 2012, 2 2433.

[67] Agnihotri, S. A.; Mallikarjuna, N. N.; Aminabhavi, T. M. J. Control. Release 2004, 100, 5.

[68] Siepmann, J.; Peppas. N. A. Adv. Drug Deliv. Rev. 2011, 48, 39.

[69] Wang, Q.; Zhang, J.; Wang, A. Carbohydr. Polym. 2009, 78, 731.

[70] Ding, Y.; Shen, S. Z.; Sund, H.; Sun, K.; Liua, F.; Qi, Y.; Yan, J. Mater. Sci. Eng. C. 2015, 48, 487.

[71] Liu, T. Y.; Hu, S. H.; Liu, T. Y.; Liu, D. M.; Chen, S. Y. Langmuir 2006, 22, 5974 .

[72] Hu, S. H.; Liu, T. Y.; Liu, D. M.; Chen, S. Y. J. Control. Release 2007, $121,181$.

[73] Huang, Y.; Liu, M.; Chen, J.; Gao, C.; Gong, Q. Eur. Polym. J. 2012 $48,1734$.

[74] Urbina, M. C.; Zinoveva, S.; Miller, T.; Sabliov, C. M.; Monroe, W. T.; Kumar, C. S. S. R. J. Phys. Chem. C 2008, 112, 11102.

[75] Zhou, L.; He, B.; Zhang, F. Appl. Mater. Inter. 2012, 4, 192.

[76] Likhitkar, S.; Bajpai, A. K. Int. J. Polym. Mater. Polym. Biomater. 2014, 63, 941.

[77] Gupta, R.; Bajpai, A. K. J. Appl. Poly. Sci. 2009, 114, 3548. 